\title{
https://doi.org/10.48009/1_iis_2009_136-140 \\ DELIVERING ERP LEARNING TO STUDENTS IN A UNIVERSITY BUSINESS PROGRAM
}

\author{
Adnan A. Chawdhry, California University of Pittsburgh, chawdhry_a@cup.edu \\ Michael J. Donohoe, University of Pittsburgh, mdonohoe@pitt.edu
}

\begin{abstract}
In years past, Information Technology (IT) had been viewed as a separate business function from the rest of the enterprise. But today, as companies are forced to move from functional silos to integrated processes, with a greater dependence on complex information technology systems in search of a global competitive advantage, moving data within the business as well as to their up-stream suppliers and down-stream customer's environments, a trend has emerged; more organizations are implementing Enterprise Resource Planning (ERP) systems to better manage and coordinate their business functions, information, and resources. In addition to ERP, other similarities are also evolving within companies in the areas of Customer Resource Management (CRM) as well as Supply Chain Management (SCM). By combining these three systems together, a complex end-to-end view of data is created, from the suppliers of raw materials, to the manufacturer's build process, out to the customer order entry process; all with the singular purpose of design to improve the cost, quality and speed of production, that delivers a valued product to the customer, while generating a profit for the business.
\end{abstract}

This migration of business Management Information Systems (MIS) and Information Technology (IT) platforms within the business world towards ERP solutions, to sustain and advance current (and future) demands of a successful global business model, has created a challenge for university business schools (and their students) by continually meet the demands of future business employment in preparing students with the knowledge and skills needed to be successful and valued. As curriculum development processes are considered, just like in the business environment where the ERP system is now recognized as cutting across functional silos to create greater visibility and control of process streams, universities are now giving thought on how ERP system training could be used to span the business school functional silos, creating a backdrop or platform for curriculum redesign, trending towards industry process alignment evolving the overall business value chain. Just as universities adapt to ERP Systems within the business environment, the business students will also need to gain a greater awareness of ERP systems and how they are used in business, as they seek advisement into career tracks and plan for their future role within the business or global enterprise.

This paper discusses the university ERP curriculum development process, based on industry ERP employment training models, resulting in recommended guidelines for the effective delivery of ERP learning at a higher education institution, aimed at teaching business students the fundamentals of ERP systems. This paper focuses only on delivering ERP to the students in a business program, but can also be considered when thinking about CRM, Logistics Systems, and SCM Systems.

By considering this process, university faculty and students will be better informed about ERP systems and become a better asset to any organization that employs them.

Keywords: Enterprise Resource Planning (ERP), Customer Resource Management (CRM), Supply Chain Management (SCM), Business Process Alignment, SAP, FDA, University, Business Program.

\section{INTRODUCTION}

An ERP system is a multi-million dollar investment that fails if the system is not used as intended [3]. These systems require a specific level of training, depending on the employees' work responsibilities, to educate the employees on how to properly use the system. Additionally, organizations that are federally mandated ensure that their employees properly utilize the ERP system in order to avoid warnings or penalties given by federal agencies for not complying with governmental requirements and guidelines. However, competition and economic conditions drive the initiative for organizations to lower their expenses, which include decreasing or eliminating money budgeted for training. For these reasons, organizations are looking for potential applicants with prior ERP knowledge because it will reduce the amount of training needed to train the employee on the ERP system. In an effort to better equip potential 
job applicants with ERP knowledge, universities and colleges are now seeking ways to incorporate ERP learning into their business curriculum, thus providing graduates with a competitive edge when seeking employment.

\section{CURRICULUM ALIGNMENT TO BUSINESS}

\section{ERP Systems Overview}

In the early 1990s ERP systems originated as integrated functions of Material Requirements Planning (MRP), Material Resource Planning functions, as well as Computer Integrated Manufacturing (CIM) systems, used by manufacturing companies to improve production process in the area of scheduling requirements for materials as shop floor resources. Over time, additional functionality has been added to include Product Lifecycle Management (PLM), Financials, Accounting, SCM (Purchasing, Material Management, \& Logistics), Human Resources, CRM and Data Warehouse or Business Intelligence. Brining these systems on-line in the company take tremendous resources in the form of people, time, and money. Most often, existing business functionality and processes are converted to take advantage of the ERP systems out of the box 'industry best practices' functionality. To maintain system effectiveness once installed, most often dedicated Information Technology analysts are employed to maintain both the physical equipment running the ERP system but also business analysts who support the application functionality supporting existing ERP features as well as creating new functionality. Additionally, end users, professionals working within various functions within the business, also need to know how the system works, must understand the various data structures, as well as be able to navigate the various screens to do their daily work effectively.

\section{Selecting the Right ERP System}

As universities consider different ERP system providers to build the business school curriculum upon, they will discover three vendors quickly come to the top of the list; SAP, Oracle, and Microsoft. All three vendors have some form of university effort underway. However, for this paper, we will focus on SAP. SAP has been selected as the university ERP platform for this paper, because of it having the largest market share of global deployed ERP systems operating in a production environment and for its well established University Alliance Program [6]. The Alliance program supports universities with hosted SAP services, running current ERP software used by industry, in an education production environment, that supports concurrent classroom needs. This effort, only requires the SAP GUI client to be installed on the students computer (via an Internet connection), no longer requiring the university to acquire the necessary hardware and skills needed to run a training service within their limited university budgets. This similar platform was unthinkable ten years ago, holding many schools back from considering this type of curriculum development. By integrating a blended training approach of the university classroom lecture, with inclass hands on simulation, as well as self-directed student study via internet connection with SAP course simulation software materials, the student is placed in a learning centric environment, optimizing a blended learning solution, conducive to learning situations with today's business professionals [1].

\section{SAP Background}

SAP was founded in 1972, by five former IBM employees in Mannheim, Germany. Today, the company has a 48,216.39(million) Market Cap, is headquartered in Walldorf, Germany (with North American Headquarters in Newtown Square, Pennsylvania) and is listed on both the Frankfurt Stock Exchange as well as the NYSE under the symbol SAP. Their ERP software is running in 120 countries and has over 86,000 customers. In a 2007 Gartner, Inc. ranking, based on total software revenues, SAP was ranked \#1 in market share in: $\mathrm{CRM}$ at $25.35 \%$, SCM at $22.4 \%$, and ERP at $27.5 \%$ [5]. With SAP's significant global presence in the business community, based on thousands of deployed ERP systems, universities today are reconsidering selecting the hosted ERP education solution because of the thin-connection into the student's computer, a large University Alliance Support function that provides current curriculum in many business function areas (Accounting, Supply Chain Management and Human Resources), as well as hands-on simulation applications that cross many business functions, as realized in today's business environment.

\section{Government Regulations Help Shape Business Applications}

Many organizations are bound by federal regulations that ensure that the company utilizes its business systems as they were intended. Any mistakes that are made with these business systems, including ERP systems, can lead to government agencies penalizing 
the organization for not complying with government regulations. Medical device manufacturing facilities must abide by government regulations such as Sarbanes-Oxley, which are enforced by the Food and Drug Administration

An example of regulatory oversight is how the FDA regulates companies that produce medical devices that are sold within the United States; with a focus on protecting the patients from potential harm. Any company that is within the scope of medical device product FDA regulations is subject to an audit, which can occur at any time. FDA audits are used to ensure that companies producing medical aides are compliant with the regulations set forth by the United States government [2]. If the FDA discovers that the company has violated any regulations, then they will present the company with a formal warning detailing the corrective action needed for compliance [7]. Failure to resolve the issues identified by the FDA audit would then lead to a number of penalties, even to the point of shutting down the facility, consent decrees, loss of jobs for the employees, and indictment of company officers [7].

\section{Corporate Training of SAP}

A medical device manufacturing facility located in the mid-Atlantic region recruits potential job applicants who have prior SAP experience. By finding applicants who posses prior experience, the organization can decrease or eliminate the entry level SAP training classes and lower their training costs. Additionally, the organization changed their training program to incorporate interactive learning, thus providing a more efficient method of training their employees. These changes were facilitated decreasing the company's training expenses and to ensure that employees who needed SAP training learned how to use the system as defined by the company procedures.

The organization offered SAP training classes in two formats: (1) classroom training and (2) interactive online training. The classroom training was used for more advanced /SAP functionality, where employees needed guidance while they were learning and practicing these concepts. The online training classes were used to educate the employees on routine tasks in SAP such as recording project time, creating materials, and other day-to-day activities. However, based upon the observations conducted at this organization, various employees felt that the training was designed and intended for employees who had a fundamental understanding of SAP, what it did, and how it worked.

In the classroom setting, each class was taught by one or two instructors with 10 to 20 students per class. Each class lasted between one and two hours. The classes were taught in a room that was setup with 20 laptops for each of the employees to use during the training. During the class, the instructor used a combination of PowerPoint slides and a sandbox training system to teach the employees how to use the system according to the company procedures. The sandbox training system was a system used for the purposes of conducting and practicing concepts from the training and was a copy of the live SAP system. The live system contained information and activities related to the company's daily operations.

Every three months, this company overwrote the contents of the sandbox training system with the information copied over from the live SAP PDM system to allow the future training sessions to utilize up-to-date information.

The company minimized the frequency of the instructor led training classes six months after the SAP implementation. This decision was made because the employees hired prior to the implementation completed their required training and only new employees or those who transferred positions would require it thereafter. The frequency of the classes went from multiple times a week to once a month or once every two months depending on how many employees needed training. In these less frequent training sessions, employees were expected to bring their own laptops or share a laptop with another person. Additionally, the classes were designed with the intention to allow employees ample time to practice their learned concepts in the sandbox training system. Lastly, the training utilized a quiz that was verbally answered by employees in the class as proof that they had learned the concepts taught during the session.

In January 2007, the company implemented an online training system using a software package named "OnDemand" designed by a company called Global Knowledge. This company was a small sized company that was bought-out by a larger company called Oracle on July 31, 2008. In October 2008, Oracle changed the name of future releases for this application to Oracle User Productivity Kit [4]. OnDemand is a web-based training tool designed to develop, manage, and deploy training to employees [4]. This software package allowed employees to complete training at any time using an interactive 
online format that simulated steps from the training class.

The OnDemand training was comprised of three parts: "See It", "Try It", and "Know It." The See It section played a pre-recorded video, which simulated the steps in the SAP training that the employee performed to complete the associated tasks. In this section, each step had a small bubble that appeared explaining what to do for that given task. Once this section was completed, the employees started the second section manually by clicking on the link called Try It. In this section, each step displayed a bubble with an explanation of what the employee needed to do for that task. Unlike watching the steps in the See It section, the employees performed each step interactively in the Try It section. Each step that the employee completed in the Try It section had a red box around the area that needed a mouse click or a typed input. If the employee clicked in the wrong area, the training notified him/her that the action was incorrect.

After the employees completed the Try It section, they were required to complete the final Know It section, which they accessed by manually clicking the Know It link. It is important to note that the employees were permitted to retake the See It and Try It sections as many times as they desired to better learn the training concepts. The Know It section expected the employee to complete the tasks in the same order that was done in the See It and Try It sections. This section provided very limited instructions other than the information regarding the values that needed to be entered. These values included information such as a transaction code or a password. The employee was expected to complete this section with a score of $70 \%$ or better, otherwise they would not receive credit and would have to take the Know It section again until they successfully passed. Once passed, these results were recorded on each employee's training record. After employees passed the training classes required for their positions, the training department would notify the SAP security group that the employee had successfully completed the required training. The security group then assigned the associated security access to that employee within SAP.

\section{DISCUSSION}

Over the past ten years, universities have implemented technologies that allow them to partner with companies that develop ERP solutions to incorporate a curriculum that better equips their students for careers within industries that utilize ERP applications. However, university business schools must integrate their ERP curriculum with external partnerships to enhance the students learning and understanding of these systems. This initiative can be accomplished by amalgamating the traditional methods of classroom instruction with online tools, interactive practice, and providing real world scenarios.

Since ERP systems are complex in nature, a preferred education is to utilize a live instructor who can guide the students and provide them with instantaneous support. This instruction can be enhanced with the use of online simulations that are created with programs such as OnDemand. These simulations allow for the students to view individual steps at their pace if instructor lead education does not accommodate their level of knowledge and expertise. It is crucial that these concepts be practiced while mimicking real world scenarios in order for the students to better understand how the ERP application fits and benefits a company's needs.

The above recommendation will considerably improve a student's understanding of what and how ERP systems are used. However, universities can provide a much stronger comprehension of ERP systems if they provide an application environment, similar to one used in companies, for the students to practice learned concepts. While many universities believe this application environment would be too costly, programs such as the SAP University Alliance provide this environment. By utilizing this effort, universities can circumvent budgetary concerns and offer an environment that replicates an environment used at companies around the world.

\section{CONCLUSSION}

This research effort provides university faculty who are considering ERP system integration into their business school curriculum with insight into industry demand for skilled knowledge workers who have business school education as well as applied knowledge and understanding of ERP systems and how they drive across all functions within business.

By having a better understanding how a business conducts employee training, universities may be better prepared to align their business curriculum based on a functioning ERP system as a catalyst for change. As an example, by using the SAP University Alliance ERP system in a MIS business course that would be required by all business majors, the student would learn how to navigate an ERP System and better understand the broad functional areas it supports. Then, as the student advances within the business school, the knowledge gained in the 
business MIS course, would enable advance learning into several business disciplines: Operations Management, Accounting, Supply Chain Management, Quality, and Human Resource, providing the student with a broad business knowledge as well as SAP ERP knowledge. Students completing this work would have a greater understanding of how ERP Systems advance the business, as well as possible certification (TERP10) that is highly valued in the marketplace today. Future research efforts could explore internal university barriers towards this type of curriculum integration as well as the additional ERP training that non-MIS faculty would need to be successful in blending ERP system process into their current courses.

\section{REFERENCES}

1. Donohoe, M. (2004). Transforming Remote Sales Force Training: Framework for Integrating E-Learning into an Existing Remote Sales Force Training Program - A Case Study.

2. FDA (2009). Frequently asked questions (faqs) Retrieved on March 2, 2009 from http://www.fda.gov/opacom/faqs/faqs.html
3. Goldband, B. (2009). The real reasons why erp systems fail. Retrieved on March 2, 2009 from http://www.reliableplant.com/article.aspx?ar ticleid $=10733 \&$ pagetitle $=$ The + real + reasons +why+ERP+systems+fail

4. Oracle (2009). Oracle user productivity kit professional. Retrieved on March 7, 2009 from

http://www.oracle.com/applications/tutor/us er-productivity-kit-pro.html

5. SAP Holds Top Rankings in Worldwide Market Share for Business Suite Applications, Retrieved June 17, 2009, from SAP AG's Corporate International Web site: http://www.sap.com/about/newsroom/newsreleases/press.epx?pressid=9913

6. SAP University Alliances, Retrieved June 17, 2009, from SAP AG's Corporate International Web site: https://www.sdn.sap.com/irj/scn/uac

7. STS(2008). Computer system validation its more than just testing. STS Consulting Retrieved on April 1, 2008 from http://www.stsv.com/pdfs/STS_CSV_article . .pdf 